УДК $631.438 .2 ; 544.034 .24 ; 532.5-1 /-9$

\title{
О ВОЗМОЖНОСТИ ИСПОЛЬЗОВАНИЯ ГЛИНОСОДЕРЖАЩИХ БАРЬЕРНЫХ МАТЕРИАЛОВ ДЛЯ ЛОКАЛИЗАЦИИ ПОСЛЕДСТВИЙ РАДИАЦИОННЫХ АВАРИЙ (НА ПРИМЕРЕ АЭС «ФУКУСИМА-ДАЙИТИ»)
}

\author{
Антоненко Михаил Викторович1, \\ antonenkomv26@mail.ru
}

\author{
Беспала Евгений Владимирович1, \\ bespala_evgeny@mail.ru
}

\section{Мышкин Вячеслав Фёдорович2, gos100@tpu.ru}

\section{Павлюк Александр Олегович 3 , seversknet@rambler.ru}

1 Горно-химический комбинат, Россия, 662972, г. Железногорск, ул. Ленина, 53.

2 Национальный исследовательский Томский политехнический университет, Россия, 634034, г. Томск, пр. Ленина, 30.

${ }^{3}$ АО «Опытно-демонстрационный центр вывода из эксплуатации уран-графиттовых ядерных реакторов», Россия, 636000, г. Северск, ул. Автодорога 13, 179а.

4 Институт физической химии и электрохимии им. А.Н. Фрумкина Российской академии наук, Россия, 119071, г. Москва, пр. Ленинский, 31, корп. 4.

\author{
Котляревский Сергей Геннадьевич ${ }^{3}$ \\ skotkyarevkiy@rambler.ru
}

\author{
Захарова Елена Васильевна 4 , \\ zevchem@rambler.ru
}

\author{
Волкова Анна Генриховна 4 , \\ anna.agv@yandex.ru \\ Беспала Юлия Рашидовна 2,1 , \\ yrbespala@gmail.com
}

\begin{abstract}
Актуальность работы обусловлена необходимостью выбора эфффективных подходов и новых инновационных барьерных материалов, обладающих противофильтрационными и противомиграционными свойствами, для локализации последствий аварий на радиационно опасных объектов.
\end{abstract}

Цель: обзор возможности использование отечественных технологий по локализации радионуклидов внутри пунктов размещения радиоактивных отходов и ядерных материалов (кориума) для решения проблемы миграции радионуклидов на АЭС «Фукусима-Дайити».

Методы: математическое моделирование процесса миграции радионуклидов из разрушенных энергоблоков атомной электростанции «Фукусима-Дайити» (АЭС «Фукусима-Дайити») через глиносодержащие барьеры безопасности.

Результаты. Рассмотрена возможность использования барьерных материалов для локализации последствий радиационных аварий. На основе положительного отечественного опыта предложено использование барьеров безопасности на основе глинистых композиций и гелеобразующих растворов для предотвращения подземной миграции радионуклидов из разрушенных энергоблоков в окружающую среду. В качестве примера такой ситуации выбрана произошедшая 11 марта 2011 г. авария на АЭС «Фукусима-1», которая в настоящее время является объектом для отработки технологий и подходов ликвидации аварий. В работе описаны основные источники радиоактивного загрязнения, образованные в результате аварии на АЭС «Фукусима-Дайити» и распространяющиеся грунтовыми водами, дождевыми потоками и охлаждающей водой, которую закачивают в поврежденные активные зоны. Выявлены недостатки использующейся системы барьеров безопасности, основанной на заморозке грунтов. На основе положительного отечественного опыта предложено использование глиносодержащих барьеров безопасности для предотвращения мигращии радионуклидов из разрушенных энергоблоков в океан. Для этих иелей рассмотрены такие природные материалы, как вермикулит, перлит, цеолит, шунгит, и определены их сорбционные характеристики. Представлены результаты математического моделирования процесса миграции наиболее мобильных радионуклидов (Ри, Cs, Sr, U) через барьерные материалы из глины. Показана возможность использования барьера безопасности на основе смеси глин. При этом ширина такого барьера не превышает 3,7 м (определяется скоростью миграции урана). Общий объём глиносодержащего барьерного материала, необходимого для предотвращения миграции радионуклидов, составляет 145900 м³. Для замедления миграции трития предложен противофильтрационный барьер на основе гелеобразующего раствора. В качестве геля возможно использование специальных растворов, содержащих продукты разложения геологических пород ийолитуртитовой группы. В результате разложения в растворе образуются щелочноземельные, переходные и щелочные элементы, ионы $\mathrm{Al}$ и $\mathrm{H}_{4} \mathrm{SiO}_{4}$. Предлагается использовать указанный гель путем его инжекции вокруг энергоблоков АЭС «ФукусимаДайити». Это позволит полимеризировать ортокремневую кислоту, что приведёт к адсорбции катионов $\mathrm{Ca}, \mathrm{Mg}, \mathrm{Fe}$ и гидратированного алюминия.

Ключевые слова:

АЭС «Фукусима-Дайити», авария, барьеры безопасности, глина, миграция, радионуклид.

\section{Введение}

Общеизвестно, что 11 марта 2011 г. у берегов Японии в Тихом океане произошло землетрясение, которое инициировало цунами, высота волны которого была более 10 м. В результате столкновения цунами с побережьем северо-восточной части острова Хонсю было 
нарушено функционирование системы охлаждения реакторов типа BWR на атомной электростанции «Фукусима-Дайити», расположенной в городе Окума уезда Футаба префектуры Фукусима [1-4]. В момент землетрясения три энергоблока были остановлены, но состояние штатных систем безопасности станции в наступивших условиях не позволило организовать достаточное аварийное охлаждение активных зон. Процесс остаточного энерговыделения сопровождался интенсивным парообразованием. Вследствие взаимодействия пара с циркониевыми конструкционными элементами происходило накопление водорода (пароциркониевая реакция) $[5,6]$ в активных зонах реакторов. Согласно данным, представленным в работе [7], количество водорода в энергоблоке I-1 за первые 10000 секунд после аварии возросло до 450 кг, а в I-3 - 1200 кг.

В результате накопления водорода в активной зоне реактора 12 марта на первом энергоблоке АЭС «Фукусима-Дайити» произошёл взрыв. В последующие дни аналогичным образом были повреждены энергоблоки I-2 и I-3. Согласно сравнительному анализу последствий аварии на Чернобыльской АЭС и на «Фукусима-Дайити», представленному в работе [8], общее радиоактивное загрязнение в результате последнего инцидента составило $\sim(340-800) \cdot 10^{15}$ Бк. К основным радионуклидам, поступившим в окружающую среду, можно отнести: ${ }^{85} \mathrm{Kr}-44$ ПБк [9]; ${ }^{133} \mathrm{Xe}-$ 14 ПБк [10]; ${ }^{132} \mathrm{Te}-180$ ПБк [8]; ${ }^{131} \mathrm{I}-(65,2-380)$ ПБк $[11,12] ;{ }^{133} \mathrm{I}-146$ ПБк [8]; ${ }^{134+136+137} \mathrm{Cs}-$ до 92,5 ПБк $[13-15] ;{ }^{239+240} \mathrm{Pu}-(1-2,4) \cdot 10^{-6}$ ПБк $[16] ;{ }^{241} \mathrm{Pu}-$ $(1,1-2,6) \cdot 10^{-4}$ ПБк [16]. В результате аварии область диаметром $\sim 60$ км получила обширное радиоактивное загрязнение с плотностью, например, по ${ }^{137} \mathrm{Cs}$ более

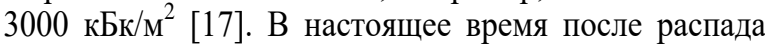
короткоживущих радионуклидов основной вклад в загрязнение вносят радионуклиды ${ }^{239,240,241} \mathrm{Pu},{ }^{235,238} \mathrm{U}$, ${ }^{134,137} \mathrm{Cs},{ }^{90} \mathrm{Sr},{ }^{3} \mathrm{H}$ и др.

Радиоактивные продукты деления и активации из активной зоны реакторов I-1, I-2, I-3 под действием взрывной волны, ветра и выпадения атмосферных осадков осели в прилегающих к станции горных массивах и лесах [18]. В настоящее время вместе с грунтовыми водами и дождевыми потоками радионуклиды поступают в океан. При этом, несмотря на предпринятые меры по удалению поверхностного слоя грунта, количество поступающих в океан радиоизотопов цезия практически не сократилось [19]. Данный факт свидетельствует либо о более глубоком загрязнении почвы, либо о наличии очагов преобладающей локализации радионуклидов с неконтролируемым поступлением в окружающую среду.

Другим источником радиоактивной воды, поступающей в Тихий океан, стало реакторное пространство с ядерным топливом в виде кориума, которое требует длительного охлаждения. В результате поступления жидкости в активную зону шли процессы выщелачивания и миграции за пределы реакторного пространства практически всех имеющихся радионуклидов из кориума, остатков топлива и конструкционных элементов $[20,21]$. Через трещины и под действием капиллярного движения влаги через почву вода достигала океана [22, 23].

Для предотвращения дальнейшего загрязнения грунтовых вод и попадания радиоактивного загрязнения в Тихий океан эксплуатирующая компания ТЕРСО в 2015 г. принимает решение заморозить грунт (снимок Google Maps [24] на рис. 1). На исходный рисунок из Google Maps были нанесены линии, означающие следующее: красная линия - периметр размещения энергоблоков, голубая линия - первый периметр заморозки грунта, оранжевая линия - второй периметр заморозки грунта. Слой почвы, прилегающий к энергоблокам, замораживали путем подачи циркулирующего хладагента в морозильные трубы, установленные по периметру месторасположения АЭС на глубине 30 м [25]. В конце марта 2016 г. практически полностью была завершена заморозка грунта со стороны берега (оранжевая линия).

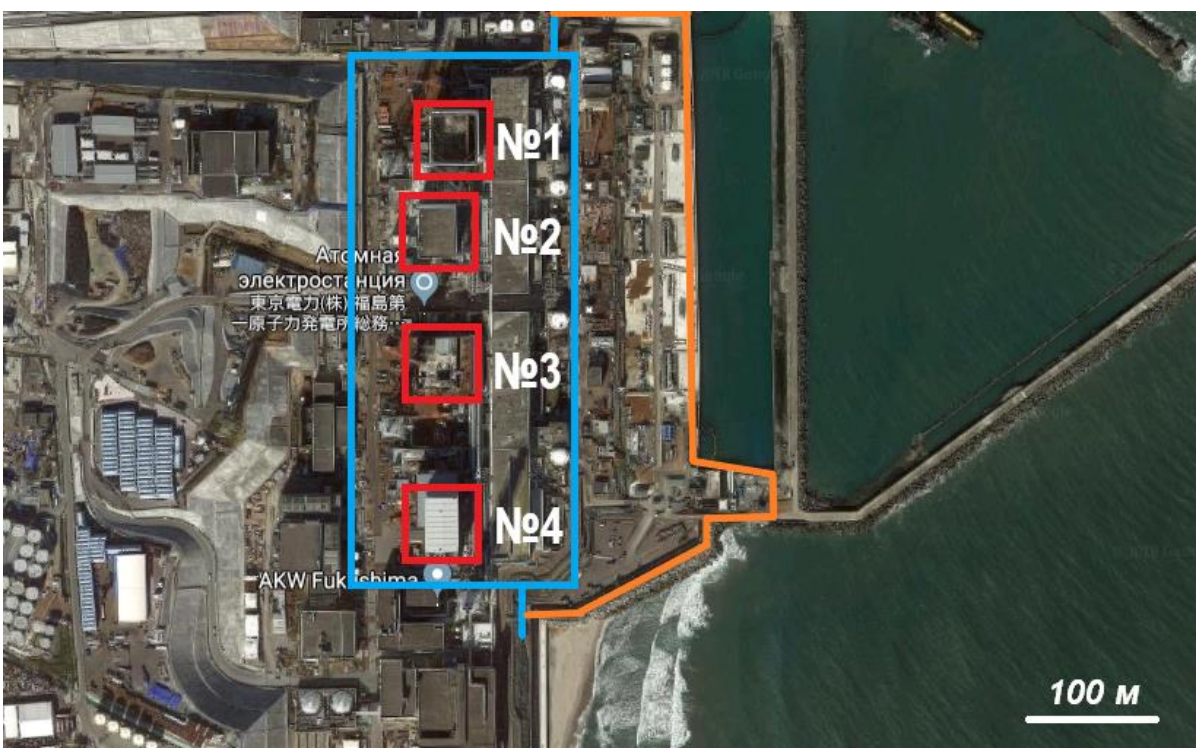

Pис. 1. Схема заморозки грунта в месте аварии на АЭС «Фукусима-Дайити»

Fig. 1. Scheme of ground frost at the accident site at the Fukushima Daiichi NPP 
Однако использование системы заморозки грунта с целью предотвращения миграции радионуклидов в океан представляется энергозатратной из-за необходимости непрерывной циркуляции хладагента с помощью насосов. В настоящее время данная технология рассматривается как временная мера предотвращения миграции до разработки и применения технологий извлечения кориума из реакторов. Работы по извлечению топлива предполагается осуществить в ближайшие 10-15 лет.

При этом необходимо учитывать, что в случае невозможности завершения работ по извлечению топлива в краткосрочный период, вероятно, возникнет потребность в применении более экономичной и надежной системы длительного сдерживания радионуклидов. Для этого целесообразно рассматривать применение геологически совместимых со средой природных барьерных материалов или комбинацию барьерного материала с замороженным грунтом, что является глубоко эшелонированной защитой [26]. К таким барьерам, прежде всего, относится глина [27-29].

Стоит отметить, что уже ранее предлагалось использовать бентонитовую глину для создания барьеров безопасности непосредственно в корпусе реактора и изоляции радионуклидов внутри него [30, 31] Было определено, что гидравлическая проводимость используемого бентонита составляет $10^{-10}-10^{-8} \mathrm{M} / \mathrm{c}$. При этом не было показано, что предлагаемый барьерный материал обладает противомиграционными свойствами. Более того, экспериментальное моделирование процесса локализации расплавленного ядерного топлива выявило нестабильность и ухудшение гидроизоляционных свойств бентонитовой глины. Заполнение реакторных пространств в текущих условиях является сложнейшей инженерно-технической задачей, связанной с большими дозовыми нагрузками на работающий персонал и задействованное оборудование. Поэтому целесообразно создавать барьеры безопасности за пределами места размещения разрушенной реакторной установки.

\section{Опыт использования глиносодержащих} барьерных материалов в России

По номенклатуре Международной минералогической ассоциации (ММА) глинистые минералы относятся к силикатам (подкласс филлосиликатов) и содержат две группы [32]. Эти группы различаются по количеству тетраэдрических и октаэдрических сеток - 1:1 (каолинит, галлуазит, лизардит, бертьерин и др.) или 2:1 (группа истинных слюд (мусковит, биотит, флогопит и др.), слюды с дефицитом межслоя (иллит, глауконит), смектиты (монтмориллонит, сапонит и др.), вермикулиты (вермикулит), группа хлоритов (клинохлор, шамозит и др.)), а также по количеству изоморфных замещений, определяющих заряд слоя. Минералы типа 1:1 имеют низкие емкость и набухаемость, а также высокую водопроницаемость (высокая диффузия). Минералы типа 2:1 содержат катионы и молекулы воды в составе межслоевого промежутка (межслоя). Каолиниты характеризуются низкой емкостью катионного обмена, слабой набухаемо- стью и противофильтрационными свойствами. Минералы группы смектита, в первую очередь монтмориллонит (имеющий относительно низкий заряд слоя и локализацию изоморфных замещений в октаэдрическом слое), способны к внутрикристаллическому набуханию и хорошо сорбируют катионы и анионы на базальной поверхности и боковых сколах. На рис. 2 приведены два слоя атомов, формирующих иллит. Слои глинистых минералов объединяются в объемное тело за счет межмолекулярных сил, обусловленных нескомпенсированными зарядами на базальных (плоских) поверхностях каждого слоя [33, 34]. Это связано с тем, что отрицательно заряженные центры двух слоев притягиваются за счет взаимодействия с межслоевыми ионами $\mathrm{K}^{+}$. При этом содержащийся в природной глине $\mathrm{K}^{+}$может заменяться на ионы щелочных или щелочноземельных металлов, удерживаемых внутри минерала глины.

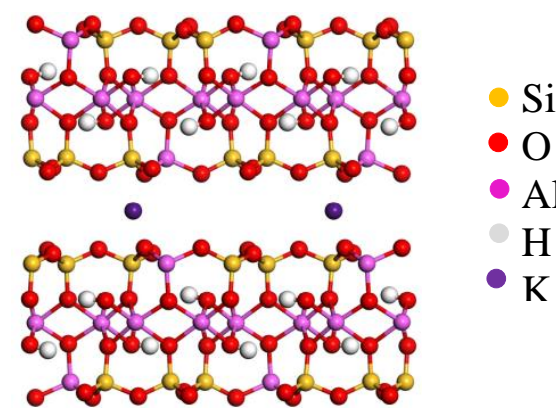

Pис. 2. Молекулярная модель фрагмента двух слоев минерала иллита

Fig. 2. Molecular model of a fragment of illite mineral two layers

Глиносодержащие материалы широко применяются в Российской Федерации для создания искусственных барьеров безопасности в пунктах хранения и захоронения РАО. Наиболее показательным является использование глин при выводе из эксплуатации промышленного уран-графитового реактора (ПУГР) ПУГР ЭИ-2, расположенного в г. Северске Томской области, по варианту «Захоронение на месте» $[35,36]$, а также ПУГР АД, расположенного в г. Железногорске Красноярского края $[37,38]$. Планируется использование схожих по составу глиносодержащих барьеров безопасности для вывода из эксплуатации ПУГР АДЭ-1 и И-1.

Кроме того, глиносодержащие барьерные материалы использовались для ликвидации водоёмовхранилищ жидких РАО. С целью сокращения поступления радиоактивных аэрозолей в атмосферу и загрязнения подземных вод был сначала законсервирован, а потом выведен из эксплуатации с применением глин и суглинков водоём В-9 (Карачай), расположенный на промышленной площадке ФГУП «ПО «Маяк» (Челябинская область) [39, 40]. Также путем создания послойной засыпки из защитного барьерного материала (экрана и внешних барьеров безопасности) был выведен из эксплуатации бассейн-хранилище жидких PAO № 354 ФГУП «ГХК», планируется создание глинистых барьеров безопасности в объекте 365. 
В ходе проведенных научно-исследовательских работ установлено, что уплотненные свыше 1,5 г $/ \mathrm{cm}^{3}$ образцы выбранного глиняного материала практически непроницаемы для воды. При этом содержание илистой фракции в образцах изменяется от 18 до $28 \%$ мас., тонкопылеватой фракции - от 34 до $50 \%$ масс., то есть значительная часть породы состоит из тонкодисперсного материала, емкость катионного обмена больше 30 мг-экв./100 г породы.

В илистой фракции образцов преобладают лабильные минералы (смектит, смешаннослойным иллит-смектит, вермикулит), в крупных и средних фракциях - железосодержащие фазы (самостоятельные агрегаты, пленки) и глинистые агрегаты, обладающие высокой сорбционной способностью. Многообразие типов кристаллических решеток и их структурных особенностей обеспечивает различные механизмы сорбции радионуклидов на минералах, слагающих исследуемую глину, что обеспечивает надежность фиксации на ней радионуклидов. Среди механизмов сорбции, в первую очередь, можно выделить: формирование комплексообразующих соединений с гидроксильными группами на поверхности минерала; обмен ионами; осаждение нерастворимых соединений на поверхности сорбента (адсорбция). Детальный анализ минералогического состава свидетельствует о перспективе использования образцов глины в качестве барьерных материалов: с одной стороны, многообразие вакантных позиций для сорбции, с другой высокое содержание тонкодисперсного материала, что значительно снижает его водопроницаемость за счет заиливания тонкодисперсными частицами межзерновых каналов. При этом большая часть радионуклидов ${ }^{137} \mathrm{Cs},{ }^{90} \mathrm{Sr}, \Sigma \mathrm{U}$ и $\Sigma \mathrm{Pu}$ сорбируется на барьерном материале за счёт ионообменной сорбции, скорость которой зависит от термодинамики обмена, состава и концентрации среды переноса (раствора), от природы катиона и катионной формы глины. Стоит отметить, что наиболее эффективно катионный обмен происходит из нейтральных растворов, поскольку у катионов металлов отсутствует конкуренция с $\mathrm{H}^{+}$за активные центры.

Стоит отметить, что имеется положительный опыт использования слабонабухающих минералов (иллит, вермикулит) с целью сорбции радионуклидов ${ }^{137} \mathrm{Cs}$ и $\Sigma \mathrm{Pu}[41,42]$. Сорбция ионов цезия и плутония на барьерных материалах, содержащих указанные минералы, приводит к их необратимой фиксации, поскольку происходит внедрение в тетраэдрические слои, состоящие из $\mathrm{SiO}_{2}$. Выщелочить ионы цезия и плутония из минералов можно только с помощью очень активных реагентов.

Проведенное исследование свойств широкого спектра глинистых составов привело к выводам, что барьерный материал на основе природных глин должен иметь следующие характеристики:

- влажность в диапазоне 3-4 \% мас.;

- содержание фракции с размером частиц $<0,1$ мм не менее 80 \% мас. от общего количества материала;
- емкость катионного обмена более 20 мг-экв/100 г материала;

- фактор задержки не менее 100;

- коэффициент распределения нуклидов плутония, цезия и урана более $7 \cdot 10^{2} \mathrm{~cm}^{3} / \Gamma$;

- размер зерен во фракциях, определяющих минералогический состав барьерного материала: $<0,01$ мм более 50 \% мас.; содержание фракции с размером частиц $<0,005$ мм не менее $40 \%$ мас.

Подобный глиносодержащий барьерный материал может рассматриваться в качестве основы для создания барьеров безопасности для изоляции основных объектов локализации радионуклидов разрушенных энергоблоков АЭС «Фукусима-Дайити», поскольку он обладает высокими емкостными, противофильтрационными и противомиграционными характеристиками. Барьер может быть сооружен либо путем нагнетания самоотверждающегося глинистого раствора, либо путем бесполостного заполнения пространств (имеющихся или создаваемых) самоуплотняющейся сухой мелкодисперстной смесью в местах локализации основных источников поступления радионуклидов.

Для задержки наиболее подвижных радионуклидов $\left({ }^{137} \mathrm{Cs},{ }^{90} \mathrm{Sr}, \Sigma \mathrm{U}, \Sigma \mathrm{Pu}\right)$ возможно создание проницаемых барьеров безопасности на основе вермикулита, перлита, цеолита и шунгита. Коэффициенты распределения радионуклидов $K_{d}$ на описанных материалах представлены в работах [43-45] и приведены в табл. 1.

Представленные в табл. 1 барьерные материалы обладают рядом особенностей. Так, практически каждый из них содержит неорганическую минеральную составляющую. При этом вермикулит содержит в своем составе магний, железо, кремний, алюминий и обладает высоким коэффициентом водопоглощения (100 г вермикулита способны поглотить 400-530 мл воды). Перлит и цеолит состоят из алюмосиликатов (до $16 \%$ ) и способны впитывать жидкость до $400 \%$ от собственного веса. В шунгите преимущественно содержатся оксиды кремния (до 37 \%), органические вещества (до $27 \%$ ) и оксиды алюминия (до 5 \%), что делает его универсальным и эффективным средством для очистки воды.

Таблица 1. Коэффициент межфазного распределения $K_{d}$ радионуклидов на различных барьерных материалах, $\left[\mathrm{cm}^{3} / 2\right]$

Table 1. Coefficient of interphase distribution of $K_{d}$ radionuclides on various barrier materials, $\left[\mathrm{cm}^{3} / \mathrm{g}\right]$

\begin{tabular}{|c|c|c|c|c|}
\hline Радионуклид/Radionuclide & $\mathrm{Pu}$ & $\mathrm{Cs}$ & $\mathrm{Sr}$ & $\mathrm{U}$ \\
\hline Вермикулит/Vermiculite & $3010^{3}$ & $2 \cdot 10^{5}$ & $2 \cdot 10^{4}$ & 179 \\
\hline Перлит/Perlite & $1510^{3}$ & 840 & 8 & 64 \\
\hline Цеолит/Zeolite & $1710^{3}$ & $2,2 \cdot 10^{5}$ & $6,2 \cdot 10^{3}$ & 67 \\
\hline Шунгит/Shungite & $4010^{3}$ & 306 & 7 & 206 \\
\hline
\end{tabular}

\section{Моделирование процесса миграции радионуклидов}

Согласно современным представлениям о физикохимических механизмах массопереноса радионуклидов, миграция происходит вследствие конвекции и диффузионно-дисперсионного рассеяния. При этом 
конвективный перенос, обусловленный гидравлическим градиентом, является основным механизмом распространения радионуклидов в почве. Так, в месте аварии на АЭС «Фукусима-Дайити» гидравлический градиент создается за счёт заполнения реакторного пространства разрушенных энергоблоков водой с целью охлаждения расплавленного топлива. В первый период времени ликвидации аварии в повреждённые реакторы закачивается $300 \mathrm{~m}^{3}$ морской воды в сутки. Ситуация осложняется тем, что помимо искусственного охлаждения происходит выпадение осадков в количестве (1100-1800) мм/год и поступление грунтовых вод в место аварии [46]. Таким образом, объёмная скорость поступления радиоактивной воды из каждого энергоблока в океан составляет $\sim 600 \mathrm{~m}^{3} /$ сутки [47].

При малых скоростях фильтрации особенно важен молекулярно-диффузионный перенос. Молекулярная диффузия приводит к выравниванию концентрации, в результате чего происходит перемещение вещества из более проницаемых областей в менее проницаемые области (при миграции в гетерогенных пластах глины). В результате образуются т. н. переходные зоны, в которых меняется концентрация радионуклидов и замедляется скорость их миграции [48]. Это особенно характерно для смеси глин.

Таким образом, возникает необходимость решать задачу, в которой учитывается конвективный и диффузионный перенос радионуклидов. Моделирование процесса массопереноса радиоактивного загрязнения в системе бетонное основание здания реактора - глиносодержащий барьерный материал проводилось с помощью второго закона Фика.

Решали одномерное уравнение конвективной диффузии в прямоугольной системе координат (1). При этом учитывали снижение удельной активности диффундирующих радионуклидов за счет радиоактивного распада и фильтрационного движения жидкости (влаги), содержащей радионуклиды [49]:

$$
\frac{\partial C_{i}}{\partial t}=D_{i} \frac{\partial^{2} C_{i}}{\partial x^{2}}-u_{i} \frac{\partial C_{i}}{\partial x}-\lambda_{i} C_{i}, \quad 0<x<L_{1},
$$

где $C_{i}$ - концентрация (удельная активность) $i$-го радионуклида в глиносодержащем барьере безопасности, Бк/м ${ }^{3} ; D_{i}-$ коэффициент диффузии $i$-ого радионуклида в барьере безопасности, м $2 / \mathrm{c} ; u_{i}$ - скорость движения $i$-ого радионуклида в барьере безопасности (с учетом влаги, поступающей при охлаждении активной зоны, вместе с осадками, и грунтовых вод, а также сорбции радионуклидов на материале барьера), $\mathrm{M} / \mathrm{c} ; \lambda_{\mathrm{i}}-$ постоянная распада, $\mathrm{c}^{-1} ; t$ - время, с.

Считали, что на левой границе концентрация (удельная активность) $i$-ого радионуклида уменьшается только за счёт радиоактивного распада (2):

$$
\left.C_{i}\right|_{x=0}=c_{i} \exp (-\lambda t) .
$$

Значения величины $c_{i}$ для различных радионуклидов на границе расчетной области (бетонное основание здания реактора - глиносодержащий барьерный материал) представлены в работах [50, 51]. Так, удельная активность $\Sigma$ Рu составляет 490 Бк/м ${ }^{3}, \Sigma \mathrm{Cs}-$ $1,29 \cdot 10^{9} \mathrm{Б \kappa} / \mathrm{M}^{3},{ }^{90} \mathrm{Sr}-1,14 \cdot 10^{6} \mathrm{Б \kappa} / \mathrm{M}^{3}, \Sigma \mathrm{U}-940 \mathrm{Б \kappa} / \mathrm{m}^{3}$.
Граничное условие (3) выбиралось с учётом допущения, что через время, сравнимое с периодом полураспада рассматриваемого радионуклида, он будет гарантировано отсутствовать:

$$
\left.C_{i}\right|_{x=L 1}=0 .
$$

В начальный момент времени $t_{0}$ концентрация (удельная активность) составляла $c_{i}$. Скорость движения $i$-ого радионуклида в барьере безопасности с учетом коэффициентов сорбции определялась из уравнения, представленного в работах $[52,53]$. Более подробное описание математической модели можно найти в работе [54].

Известно, что глинистые минералы обладают ионообменными свойствами. Эмпирическое соотношение (4) из работы [55] использовали для расчёта коэффициента внутренней диффузии в глинистом барьере безопасности в процессе сорбции:

$$
a_{t}=D_{i} \sqrt{t},
$$

где $a_{t}-$ величина сорбции, ммоль/ $Г$ за время $t ; D_{i}-$ константа скорости внутренней диффузии, ммоль $\cdot \Gamma^{-1} \cdot \mathrm{c}^{-0,5}$; $t$ - время сорбции, с.

Общеизвестно, что распределение радионуклидов между твердой (сорбированное) и жидкой (растворенное) фазами в равновесии описывается при помощи коэффициента распределения $\left(K_{\mathrm{d}}\right)$. Указанный коэффициент определяется как отношение концентрации сорбированного вещества к концентрации растворенного вещества после достижения равновесия между растворенной и сорбированной фазами. Значение $K_{\mathrm{d}}(5)$ может быть определено по экспериментальным данным с помощью формулы [55]:

$$
K_{d}=\frac{Q}{A}=\left(\frac{C_{0}}{C}-1\right) \frac{V}{M},
$$

где $Q$ и $A$ - массовая концентрация (в мг/г) в сорбенте и концентрация в растворе (в мг/мл) в конце эксперимента соответственно; $C_{0}$ и $C$ - начальная и равновесная концентрации в растворе; $V$ - объем жидкости, мл; $M$ - масса сорбента, г.

\section{Обсуждение результатов расчета}

Расчёт скорости миграции проводили при различной ширине глиносодержащего барьера безопасности $L$. При этом полагали, что барьер вплотную прилегает к нижней части бетонного основания здания, в котором размещаются энергоблоки АЭС «ФукусимаДайити». Результаты расчёта профиля концентрации радионуклидов в различных барьерных материалах через 10 лет после создания глиносодержащего барьера безопасности представлены на рис. 3. Из 3, а видно, что на барьерном материале на основе вермикулита эффективно сорбируются радионуклиды $\mathrm{Pu}, \mathrm{Sr}, \mathrm{Cs}$. При этом для предотвращения их попадания в океан достаточно создать барьер шириной не более 1,2 м. Общий объём используемого барьерного материала в этом случае составляет $47000 \mathrm{~m}^{3}$. Однако вермикулит обладает невысокой сорбционной способностью по отношению к изотопам урана, которые являются долгоживущими $\left({ }^{\mathrm{U}-238} T_{1 / 2}=4,5 \cdot 10^{9}\right.$ лет; ${ }^{\mathrm{U}-235} T_{1 / 2}=7,13 \cdot 10^{8}$ лет; 
${ }^{\mathrm{U}-234} T_{1 / 2}=2,48 \cdot 10^{5}$ лет). В течение 10 лет после аварии $\Sigma \mathrm{U}$ способны мигрировать на расстояние более 14 м от здания размещения реакторов. В этом случае для создания барьеров безопасности потребуется $\sim 591000 \mathrm{~m}^{3}$ глиносодержащего барьерного материала. С другой стороны, расстояние между зданием размещения реактора и местом разгрузки грунтовых вод составляет $\sim 110$ м, что говорит о невозможности попадания изотопов урана в океан во время ликвидации аварии. Это позволяет рассматривать данный барьерный материал в качестве возможного для использования на АЭС «Фукусима-Дайити».

Для создания противомиграционных барьеров безопасности менее подходящими являются глиносодержащие барьерные материалы на основе перлита (рис. 3, б). Связано это с тем, что данные барьеры практически не задерживают радионуклид ${ }^{90} \mathrm{Sr}$, который достигнет места разгрузки грунтовых вод на третий год после создания барьеров безопасности. При этом для задержки других радионуклидов потребуется глиносодержащий барьер толщиной $\sim 40$ м, а общий объём затраченного материала составит $1576800 \mathrm{~m}^{3}$, что является нецелесообразным в услови- ях сильных радиационных полей. Глины на основе цеолита более эффективны, чем на основе перлита, но менее эффективны, чем на основе вермикулита (рис. 3, в). Для задержки $\mathrm{Pu}$ потребуется барьер шириной 0,2 м, Cs - 1,2 м, Sr - 1,5 м и U - 38 м. Вследствие малой сорбционной способности урана потребуется $\sim 1498000 \mathrm{~m}^{3}$ барьерного материала для предотвращения попадания радионуклидов в океан в первые 10 лет после создания барьера безопасности. Однако наиболее непригодным барьерным материалом является шунгит (рис. 3,2 ), несмотря на то, что он используется для очистки воды в промышленности. Связано это с тем, что радионуклид ${ }^{90} \mathrm{Sr}$ достигнет места разгрузки грунтовых вод в течение 2,5 лет после установки барьера. С другой стороны, глиносодержащие барьеры безопасности на основе шунгита способы эффективно задерживать изотопы урана.

Таким образом, использование по отдельности в качестве барьерных природных материалов на основе вермикулита, перлита, цеолита и шунгита при ликвидации аварии на АЭС «Фукусима-Дайити» неэффективно с точки зрения их малой сорбционной способности части радионуклидов.
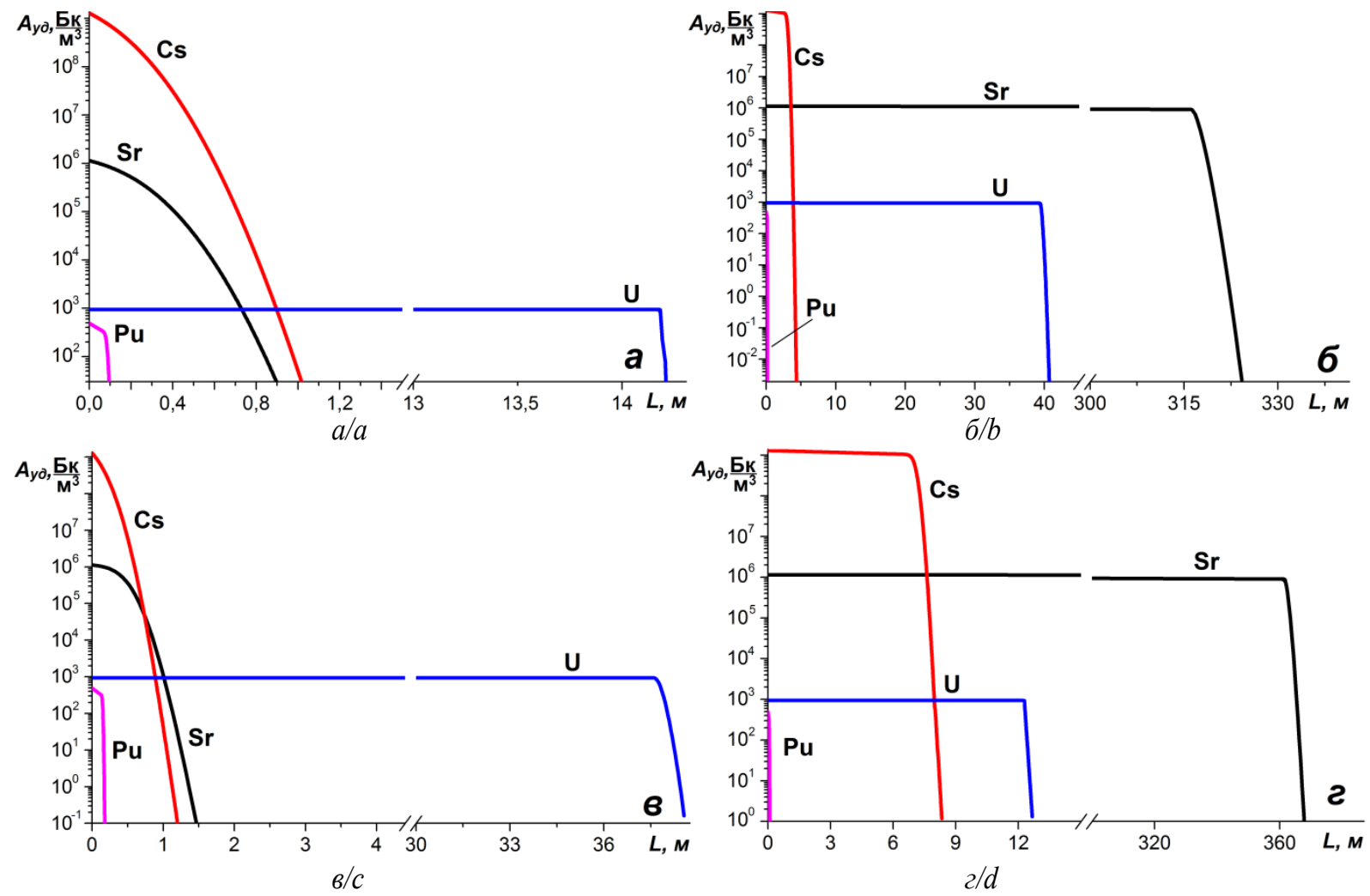

Рис. 3. Профиль концентрации радионуклидов через 10 лет после аварии на АЭС «Фукусима-Дайити» в различных материалах: а) вермикулит; б) перлит; в) цеолит; г) иунгит

Fig. 3. Radionuclide concentration profile for 10 years after the accident at the Fukushima Daiichi NPP in various materials: a) vermiculite; b) perlite; c) zeolite; d) schungite

Практически все РАО содержат тритий и более тяжелые радионуклиды. Так как ионы металлов вытесняют ионы водорода из глинистых минералов, тритий свободно диффундирует через слой глины. Фиксация трития глиной возможна в кислой среде $[56,57]$. При этом катионы металлов слабо задержи- ваются глиной. Поэтому представляется логичным использование нескольких слоев разных видов глин, модифицированными для сорбции заданного класса катионов, или смеси разных глинистых минералов, а также их комбинации с добавлением различных связующих веществ. Такие барьерные материалы ис- 
пользовались при выводе из эксплуатации ПУГР ЭИ-2 и АД. Результаты расчёта профиля концентрации в барьерном материале на основе смеси глин представлены на рис. 4.

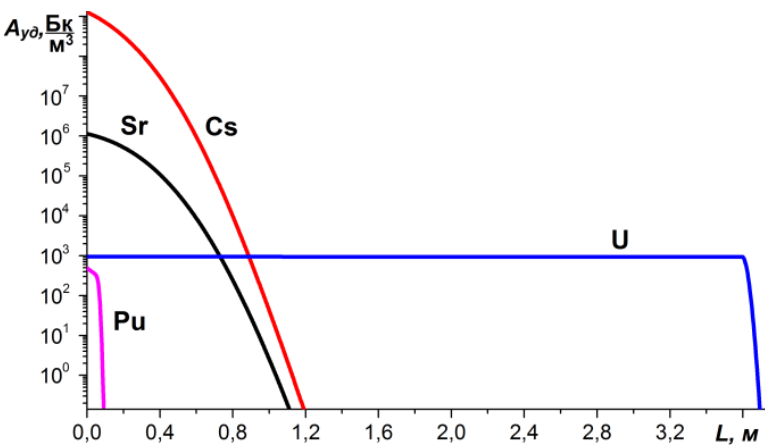

Рис. 4. Профиль конщентращии радионуклидов через 10 лет после аварии на АЭС «Фукусима-Дайити» 6 барьерном материале на основе смеси глин

Fig. 4. Radionuclide concentration profile for 10 years after the accident at the Fukushima-Daiichi NPP in barrier material based on a mixture of clays

Как видно из рис. 4, барьерный материал на основе смеси глин обеспечивает достаточно высокую сорбцию радионуклидов. При этом ширина такого барьера не превышает 3,7 м (определяется скоростью миграции урана). Общий объём глиносодержащего барьерного материала, необходимого для предотвращения миграции радионуклидов, составляет $145900 \mathrm{~m}^{3}$. Возможны другие смеси и комбинации глин для достижения более эффективной сорбции радионуклидов. Однако в конечном счёте выбор материала будет зависеть от стоимости его производства и создания барьеров безопасности. Тем не менее использование глин выглядит более привлекательным по причине отсутствия эксплуатационных расходов по сравнению с заморозкой грунта, поскольку затраты на эксплуатацию барьеров в течение всего срока службы минимальны.

Кроме того, барьерный материал на основе природных глин может быть восстановлен при его маловероятной деградации на границе области растворбарьер или осушен в случае обводнения, например электроосмотическим методом [58].

Глинистые материалы могут переходить из одного вида в другой [59]. Даже в составе одного минерала возможно одновременное существование двух видов глинистых минералов, обусловленных наличием молекул воды и различных катионов внутри кристаллита глинистого минерала [60].

\section{Возможные пути решения проблемы миграции трития}

Несмотря на перспективы использования глиносодержащих барьерных материалов для локализации последствий аварии на АЭС «Фукусима-Дайити», возникает проблема удержания радионуклида ${ }^{3} \mathrm{H}$ внутри разрушенных энергоблоков и хранилищ. При наличии других катионов радионуклид ${ }^{3} \mathrm{H}\left(\mathrm{T}_{1 / 2}=12,3\right.$ лет) не сорбируется в глиносодержащих барьерах и в бетонных конструкциях. Соответственно скорость распространения ${ }^{3} \mathrm{H}$ определяется параметрами миграции грунтовых вод. Поэтому необходим поиск смешанных глинистых минералов, позволяющих одновременно сорбировать катионы водорода, металлов, а также анионы. Предварительные результаты могут быть получены средствами молекулярного моделирования.

Тритий в кипящем водо-водяном реакторе образуется в основном при тройном делении тяжёлых ядер ${ }^{238} \mathrm{U}$ и ${ }^{239} \mathrm{Pu}$ и в меньшей степени при захвате нейтрона ядром дейтерия, а также по реакциям ${ }^{7} \mathrm{Li}(\mathrm{n}, \alpha \mathrm{n}){ }^{3} \mathrm{H}$ и ${ }^{10} \mathrm{~B}(\mathrm{n}, 2 \alpha)^{3} \mathrm{H}$. До аварии ежегодно в каждом энергоблоке генерировалось до 1 ПБк/ГВт [61]. После взрыва трёх первых энергоблоков количество выделившегося радионуклида ${ }^{3} \mathrm{H}$ составило 3,4 ПБк (1-1,2 ПБк на каждый энергоблок). При этом 0,8 ПБк находилось в технологических емкостях и бассейнах выдержки, 0,05 ПБк - в застойной воде внутри разрушенных активных зон и турбинных цехов, 0,05 ПБк - в подземных трубопроводах [62]. Удельная активность трития в застойной воде в июне 2011 г. составляла (0,7-20) МБк/л. В настоящее время общий объем воды (в том числе с ${ }^{3} \mathrm{H}$ ) в резервуарах-хранилищах на площадке АЭС «Фукусима-Дайити» составляет около $460000 \mathrm{~m}^{3}$ [63].

На сегодняшний день рассматриваются различные способы очистки накопленной радиоактивной воды от трития. Например, была предложена технология ректификации с использованием противоточных колонн, а также двухтемпературного и однотемпературного химического изотопного обмена [64]. Однако реализация предложенных методов требует организации системы обращения и транспортировки ЖРО, что может привести к миграции радионуклидов через создаваемые или созданные барьеры безопасности.

Для снижения миграции трития может быть использован, например, разработанный в России противофильтрационный барьер на основе гелеобразующего раствора [65]. В качестве геля используют раствор кислоторастворимых продуктов разложения пород группы иолита-уртита, который содержит ионы щелочных, щелочноземельных и переходных элементов, a также ионы Al. Данный раствор может быть введён в зону миграции радионуклидов в качестве преграды. В результате полимеризации $\mathrm{H}_{4} \mathrm{SiO}_{4}$, а также сорбции катионов $\mathrm{Fe}, \mathrm{Ca}, \mathrm{Mg}$ и гидратированного алюминия будет происходить формирование барьера безопасности. Создание такого барьера возможно путем инжекции гелеоразующего раствора по периметру территории вокруг разрушенных энергоблоков АЭС «Фукусима-Дайити».

В России были созданы опытные участки барьеров вокруг некоторых хранилищ твердых РАО. Последующие наблюдения показали, что в зоне использования противофильтрационного барьера коэффициент фильтрации снизился более чем на 2 порядка.

\section{Заключение}

Таким образом, результаты оценки последствий аварии на площадке АЭС «Фукусима-Дайити», анализ российского опыта создания противофильтрационных и противомиграционных барьеров безопасно- 
сти, а также результаты моделирования процесса миграции радионуклидов свидетельствуют о целесообразности использования барьерных материалов на основе глинистых композиций и гелеобразующих растворов при ликвидации аварий, подобных аварии на АЭС «Фукусима-Дайити». При этом создание барьеров на основе глинистых композиций наиболее целесообразно в местах очагов преобладающей локализации радионуклидов (шахты реакторов, окружающие конструкции, помещения, коммуникации, хранилища отработавшего ядерного топлива (ОЯТ), технологическое оборудование). Постановка противофильтрационных барьеров на основе гелеобразующих растворов будет наиболее эффективна на пути движения грунтовых вод для организации их обводного движения и обеспечения минимального их контакта со средами в зонах локализации радионуклидов.

Целесообразность создания подобных барьеров безопасности в качестве компенсационных мер по предотвращению неконтролируемого выхода радионуклидов в окружающую среду в условиях последствий рассматриваемой аварии будет определяться рядом критериев, предъявляемых к материалу барьера. А именно:

- постоянство свойств на период сохранения потенциальной опасности объекта изолируемого ядерно и радиационно опасного объекта;

- отсутствие в составе компонентов, способствующих переносу радионуклидов при эксплуатации барьера безопасности;

- низкая проницаемость влаги;

\section{СПИСОК ЛИТЕРАТУРЫ}

1. Авария на АЭС «Фукусима-1»: опыт реагирования и уроки / под общей ред. Л.А. Большова. - М.: Наука, 2013. - 246 с.

2. Арон Д.В., Павлова М.В., Панченко С.В. Оценки масштаба социально-экономических последствий аварии на АЭС в префектуре Фукусима // Известия академии наук. Энергетика. 2013. - № 5. - C. 65-71.

3. Brumfiel G. Fukushima: fallout of fear // Nature. - 2013. V. 493. - № 7432. - P. 290-293.

4. Tsunami source of the 2011 off the Pacific coast of Tohoku Earthquake / Y. Fujii, K. Satake, S. Sakai, M. Shinohara, T. Kanazawa // Earth, Planets and Space. - 2011. - V. 63. - № 7. P. 815-820.

5. Tong L.L. Hydrogen risk for advanced PWR under typical severe accidents induced by DVI line break // Annals of Nuclear Energy. - 2016. - V. 94. - P. 325-331.

6. Wang D., Cao X. Preliminary analysis of hydrogen distribution during severe accident induced by loss of coolant accident // International Conference on Nuclear Engineering, Proceedings, ICONE. - 2017. - V. 8. DOI: 10.1115/ICONE25-66497.

7. Tanabe F. Analyses of core melt and re-melt in the Fukushima Daiichi nuclear reactors // Journal of Nuclear Science and Technology. - 2012. - V. 49. - № 1. - P. 18-36.

8. Steinhauser G., Brandl A., Johnson T.E. Comparison of the Chernobyl and Fukushima nuclear accidents: a review of the environmental impacts // Science of the Total Environment. 2014. - V. 470-471. - P. 800-817.

9. Update and improvement of the global krypton-85 inventory / J. Ahlswede, S. Hebel, J.O. Ross, R. Schoetter, M.B. Kalinowki // Journal of Environmental Radioactivity. - 2013. - V. 115. P. 34-42.

10. Stohl A., Seibert P., Wotawa G. The total release of xenon-133 from the Fukushima Dai-ichi nuclear power plant accident // Journal of Environmental Radioactivity. - 2012. - V. 112. P. 155-159.
- низкие коэффициенты диффузии, высокая сорбционная способность;

- стабильность свойств барьера в различных по уровню водонасыщенности породах;

- достаточная несущая способность;

- экологическая безопасность;

- доступность;

- экономическая обоснованность.

Материалы, используемые для создания геотехногенных барьеров безопасности, должны удовлетворять условию совместимости с геологической средой, окружающей объект изоляции. В противном случае образуется неравновесная система, в которой возможны процессы, направленные на достижение геохимического равновесия с геологической средой, в которой размещен подлежащий изоляции объект. В результате данных процессов материал созданного барьера может утратить свои полезные свойства.

Следует обратить особое внимание на то, что опыт использования предлагаемых материалов на основе глин в качестве барьеров безопасности характерен для тех районов Российской Федерации, где глинистые составляющие преобладают во вмещающих породах и находятся в геохимическом равновесии с окружающей средой. Соответственно, при подборе материала барьеров безопасности для локализации последствий аварий необходимо учитывать геологогеохимические и гидрологические условия на площадке, где предполагается сооружение барьера, а также характеристики источников загрязнения.

11. Ten Hoeve J.E., Jacobson M.Z. Worldwide health effects of the Fukushima Daiichi nuclear accident // Energy and Environmental Science. - 2012. - № 5. - P. 8743-8757.

12. Estimation of errors in the inverse modeling of accidental release of atmospheric pollutant: application to the reconstruction of the cesium-137 and iodine-131 source terms from the Fukushima Daiichi power plant / V. Winiarek, M. Bocquet, O. Saunier, A. Mathieu // Journal of Geophysical Research: Atmosphere. 2012. - V. 117. - P. 1-16.

13. Hamada N., Ogino H. Food safety regulations: what we learned from the Fukushima nuclear accident // Journal of Environmental Radioactivity. - 2012. - V. 111. - P. 83-99.

14. Preliminary estimation of release amounts of $131 \mathrm{I}$ and $137 \mathrm{Cs}$ accidentally discharged from the Fukushima Daiichi nuclear power plant into the atmosphere / M. Chino, H. Nakayama, H. Nagai, H. Terada, G. Katata, H. Yamazawa // Journal of Nuclear Science and Technology. - 2011. - V. 48. - № 7. - P. 1129-1134.

15. Xenon-133 and caesium-137 releases into the atmosphere from the Fukushima Dai-ichi nuclear power plant: determination of the sourse term, atmospheric dispersion, and deposition / A. Stohl, P. Seibert, G. Wotawa, D. Arnold, J.F. Burkhar, S. Eckhardt // Atmospheric Chemistry and Physics. - 2011. - V. 11. P. 28319-28394.

16. Isotopic evidence of plutonium release into the environment from the Fukushima DNPP accident / Zheng Jian, Tagami Keiko, Watanabe Yoshito, Uchida Shigeo, Aono Tatsuo, Ishii Nobuyoshi, Yoshida Satoshi, Kubota Yoshihisa, Fuma Shoichi, Ihara Sadao. Scientific Reports. - 2012. - V. 2. DOI: 10.1038/srep00304.

17. Yoshida N., Takahashi Y. Land-surface contamination by radionuclides from the Fukushima Daiichi nuclear power plant accident // Elements. - 2012. - V. 8. - P. 201-206.

18. Depth distribution of cesium-137 in paddy field across the Fukushima pollution plume in 2013 / H. Lapage, O. Evlard, Y. Onda, I. Lefevre, J.P. Laceby, S. Avrault // Journal of Environmental Radioactivity. - 2015. - V. 147. - P. 157-164 
19. Radiocesium transfer from hillslopes to the Pacific Ocean after the Fukushima Nuclear Power Plant accident: a review / O. Evrard, J.P. Laceby, H. Lepage, Y. Onda, O. Gerdan, S. Ayrault // Journal of Environmental Radioactivity. - 2015. - V. 148. - P. 92-110.

20. Zubekhina B.Y., Burakov B.E. Leaching of actinides and other radionuclides from matrices of Chernobyl «lava» as analogues of vitrified HLW // Journal of Chemical Thermodynamics. - 2017. V. 114 . - P. 25-29.

21. Behavior of radioactive cesium during incineration of radioactively contaminated wastes from decontamination activities in Fukushima / H. Fujiwara, H. Kuramochi, K. Nomura, T. Maeseto, M. Osako // Journal of Environmental Radioactivity. 2015. - V. 178-179. - P. 290-296.

22. Wu J. Impacts of Fukushima Daiichi Nuclear Power Plant acciden on the Western North Pacific and the China Seas: evaluation based on field observation of 137Cs // Marine Pollution Bulletin. 2018. - V. 127. - P. 45-53.

23. Исследование радиоактивного загрязнения морской биоты в связи с аварией на АЭС «Фукусима-1» / В.П. Рамзаев, С.А. Иванов, Ю.Н. Гончарова, Н.М. Вишнякова, А.В. Севастьянов // Радиационная гигиена. - 2012. - Т. 4. - № 4. - С. 5-11.

24. Интерактивная карта мира // Google. URL https://www.google.ru/maps/search/Fukushima+NPP/@37.421553, $141.0304366,988 \mathrm{~m} / \mathrm{data}=! 3 \mathrm{~m} 1$ !1 3 (дата обращения 20.12.2020).

25. Current status of Fukushima Daiichi NPS. Efforts for Decommissioning and Contaminated Water Control, 2015. Available at: http://www.mofa.go.jp/files/000069784.pdf (дата обращения 29.11.2019).

26. Бутенко А.И. Нарушение уровней и барьеров глубокоэшелонированной защиты на АЭС Фукусима // ВосточноЕвропейский журнал передовых технологий. - 2012. - Т. 2/8. № 56. - C. 46-51.

27. Experimental simulation of the radionuclide behaviour in the process of creating additional safety barriers in solid radioactive waste repositories containing irradiated graphite / A.O. Pavliuk, S.G. Kotlyarevskiy, E.V. Bespala, E.V. Zakarova, N.I. Rodygina, V.M. Ermolaev, I.M. Proshin, A.G. Volkova // IOP Conf. Series: Materials Science and Engineering. - 2016. - № 142. - P. 1-7.

28. Сорбционные характеристики апатита и вермикулита по отношению к радионуклидам цезия и стронция / А.А. Кондрашова, Н.Д. Андрющенко, Е.В. Захарова, Е.А. Тюпина // Успехи в химии и химической технологии. - 2016. - Т. 30. № 6 (175). - C. 56-58.

29. Investigation and modeling of cesium(I) adsorption by Turkish clays: bentonite, zeolite, sepiolite, and kaolinite / S. Bayulken, E. Bascetin, K. Guclu, R. Apak // Environmental Progress \& Sustainable Energy. - 2011. - V. 30. - № 1. - P. 70-80.

30. Yoshikawa E., Komine H., Goto S. Evaluation on hydraulic conductivity of heavy bentonite-based slurry for using on decommissioning of the Fukushima Daiichi Nuclear Power Station // ICEG 2018: Proc. of the 8th International Congress on Environmental Geotechnics. - 2018. - V. 3. - P. 105-112. DOI: 10.1007/978-981-13-2227-3_13.

31. The quantitative evaluation for radiation shielding capabilities of soil materials / E. Yoshikawa, H. Komine, S. Goto, M. Yoshimura, A. Suzuki, S. Narushima, Y. Arai, S. Ukiie, Y. Sakoda, Y. Nagae // Journal of Japan Society of Civil Engineers, Ser. C (Geosphere Engineering). - 2017. - V. 73 (4). - P. 342-354. DOI: 10.2208 /jscejge. 73.342

32. Summary of recommendations of Nomenclature Committees relevant to clay mineralogy: Report of the Association Internationale Pour L'etude des Argiles (AIPEA) nomenclature committee for 2006 / S. Guggenheim, J.M. Adams, D.C. Bain, F. Bergaya, M.F. Bergaya, M. Brigatti, V.A. Drits, M.L.L. Formoso, E. Galan, T. Kogure, H. Stanjek // Clays and Clay Minerals. 2006 . V. 54. - № 6. - P. 761-772. DOI $10.1180 / 0009855064140225$.

33. Применение природных глинистых материалов для повышения уровня ядерной и радиационной безопасности объектов ядерного наследия / В.В. Крупская, Д.В. Бирюков, П.Е. Белоусов, В.А. Лехов, А.Ю. Романчук, С.Н. Калмыков // Радиоактивные отходы. - 2018. - № 2 (3). - С. 30-43.

34. Crystallography open database (COD): an open-access collection of crystal structures and platform for world-wide collaboration / S. Grazulis, A. Daskevic, A. Merkys, D. Chateigner, L. Lutterotti,
M. Quiro's, N.R. Serebryanaya, P. Moeck, R.T. Downs, A. Le Bail // Nucleic Acids Research. - 2012. - V. 40. - P. 420-427. DOI: $10.1093 / \mathrm{nar} / \mathrm{gkr} 900$.

35. Experience of on-site disposal of production uranium-graphite nuclear reactor / A.O. Pavliuk, S.G. Kotlyarevskiy, E.V. Bespala, E.V. Zakharova, V.M. Ermolaev, A.G. Volkova // Journal of Environmental Radioactivity. - 2018. - V. 184-185. - P. 22-31

36. Izmestiev A., Pavliuk A., Kotlyarevsky S. Application of void-free filling technology for additional safety barriers creation during uranium-graphite reactors decommissioning // Advanced Materials Research. - 2015. - V. 1084. - P. 613-619.

37. Чубреев Д.О., Кузнецов Г.В. Использование глинистых материалов для создания барьера безопасности выводимого из эксплуатации реактора АД // Известия Томского политехнического университета. Инжиниринг георесурсов. - 2016. T. 327. - № 2. - C. 83-87.

38. Антоненко М.В., Чубреев Д.О., Кузнецов Г.В. Моделирование процесса диффузии радиоуглерода из активной зоны выводимого из эксплуатации ПУГР АД // Атомная энергия. - 2015. T. 118. - C. 63-68.

39. Mokrov Yu.G., Mokrov K.Yu. Modeling of atmospheric transfer of radionuclides in the form of water aerosols from the surface area of water bodies using the example of Lake Karachay, Russia // Radiation and Environmental Biophysics. - 2019. - V. 58. P. 393-405. DOI: 10.1007/s00411-019-00799-w.

40. Мокров Ю.Г., Алексахин А.И. Мониторинг - основа обеспечения безопасности при выполнении работ по консервации водоёма Карачай // Радиоактивные отходы. - 2018. - № 3 (4). C. $60-68$.

41. Взаимодействие $\mathrm{U}, \mathrm{Np}$ и $\mathrm{Pu}$ с коллоидными частицами $\mathrm{SiO}_{2} /$ Д.Н. Батук, А.А. Ширяев, С.Н. Калмыков, Е.В. Захарова, Ю.А. Тетерин, О.Н. Батук, Б.Ф. Мясоедов // Радиохимия. 2012. - T. 54. - № 6. - C. 522-526.

42. Analysis of ${ }^{134} \mathrm{Cs}$ and ${ }^{137} \mathrm{Cs}$ distribution in soil of Fukushima prefecture and their specific adsorption on clay minerals / A. Maekawa, N. Momoshima, S. Sugihara, R. Ohzawa, A. Nakama // Journal of Radioanalytical and Nuclear Chemistry. 2015. - V. 303. - P. 1485-1489.

43. Сорбционные характеристики материалов фильтрационного барьера в верхних водоносных горизонтах, загрязненных радионуклидами / Н.Д. Андрющенко, А.В. Сафонов, Т.Л. Бабич, П.В. Иванов, Ю.В. Коневник, А.А. Кондрашова, И.М. Прошин, Е.В. Захарова // Радиохимия. - 2017. - Т. 59. - № 4. - С. 361-370.

44. Behavior of $\mathrm{Cs}, \mathrm{Np}(\mathrm{V}), \mathrm{Pu}(\mathrm{IV})$, and $\mathrm{U}(\mathrm{VI})$ in pore water of Bentonite / M.N. Sabodina, S.N. Kalmykov, K.A. Artem'eva, E.V. Zakharova, Yu.A. Sapozhnikov // Radiochemistry. - 2006. V. 48. - № 5. - P. 488-492.

45. Sorption of plutonium on geological materials associated with a Chinese radioactive waste repository: influence of $\mathrm{pH} / \mathrm{Ya}$. Leng, M.J. Henderson, J. Courtois, H. Li, K. Xiong, X. Tuo, M. Yan // Journal of Radioanalytical and Nuclear Chemistry. - 2016. V. 308. - P. 895-903.

46. Natural attenuation of Fukushima-derived radiocesium in soils due to its vertical and lateral migration / A. Konoplev, V. Golosov, Y. Wakiyama, T. Takase, V. Yoschenko, T. Yoshihara, O. Parenyuk, A. Cresswell, M. Ivanov, M. Carradine, K. Nanba, Y. Onda // Journal of Environmental Radioactivity. - 2018. V. $186 .-$ P. $23-33$.

47. Source dynamics of radiocesium-contaminated particulate matter deposited in an agricultural water reservoir after the Fukushima nuclear accident / S. Houn, S. Hayashi, J.P. Laceby, H. Tsuji, Y. Onda, O. Evrard // Science of the Total Environment. - 2018. V. 612. - P. 1079-1090.

48. Мироненко В.А., Румынин В.Г. Проблемы гидрогеоэкологии. Монография в 3-х томах. Т. 1. Теоретическое изучение и моделирование геомиграционных процессов. - М.: Изд-во Московского государственного горного университета, 1998. $611 \mathrm{c}$.

49. Shackelford C.D., Moore S.M. Fickian diffusion of radionuclides for engineered containment barriers: diffusion coefficients, porosities, and complicating issues // Engineering Geology. 2013. - V. 152. - P. 133-147.

50. Study on the leaching behavior of actinides from nuclear fuel debris / A. Kirishima, M. Hirano, D. Akiyama, T. Sasaki, N. Sato // Journal of Nuclear Materials. - 2018. - V. 502. - P. 169-176. 
51. Artificial radioactivity in environmental media (air, rainwater, soil, vegetation) in Austria after the Fukushima nuclear accident $/$ G. Steinhauser, S. Merz, D. Hainz, J.H. Sterba // Environmental Science and Pollution Research. - 2013. - V. 20. - № 4. P. 2527-2537.

52. Van Loon L.R., Mibus J. A modified version of Archie's law to estimate effective diffusion coefficients of radionuclides in argillaceous rocks and its application in safety analysis studies // Applied Geochemistry. - 2015. - V. 59. - P. 85-94.

53. Кудряшов Н.А., Серебрякова И.Е. Математическое моделирование миграции долгоживущих радионуклидов в почве в результате радиоактивных выпадений // Атомная энергия. 1993. - T. 74. - C. $243-247$.

54. Моделирование процесса миграции долгоживущих радионуклидов из графитовых радиоактивных отходов / А.О. Павлюк, С.Г. Котляревский, Е.В. Беспала, А.Г. Волкова, Е.В. Захарова, Н.Д. Андрющенко // Известия Томского политехнического университета. Инжиниринг георесурсов. - 2017. T. 328. - № 4. - C. 75-84.

55. Film and intraparticle mass transfer during the adsorption of metal ions onto bone char / K.K.H. Choy, D.C.K. Ko, C.W. Cheung, J.F. Porter, G. McKay // Journal of Colloid and Interface Science. 2004. - V. 271. - P. 284-295. DOI: 10.1016/j.jcis.2003.12.015.

56. Experimental validation of retardation of tritium migration in the Chinese Loess Media / R. Zuo, Ya. Teng, J. Wang, Q. Hu, M. Guo // Water Air and Soil Pollution. - 2011. - V. 215. - P. 497-506. DOI 10.1007/s11270-010-0494-x.

57. Сорбционная способность природного и модифицированного монтмориллонита по отношению к ионам меди в присутствии органических кислот / Е.Д. Дмитриева, А.А. Горячева, К.В. Сюндюкова, Е.Н. Музафаров // Сорбционные и хроматографические процессы. - 2016. - Т. 16. - № 6. - С. 813-820. URL: $\quad$ https://www.elibrary.ru/download/elibrary_27448864_ 32439248.pdf (дата обращения 15.06.2021).

58. Использование электроосмотического эффекта для осушения барьеров безопасности при выводе из эксплуатации ядерно- и радиационно опасных объектов / М.В. Антоненко, А.В. Лео- нов, Е.В. Беспала, Д.О. Чубреев, Ю.Р. Беспала // Известия Томского политехнического университета. Инжиниринг георесурсов. - 2019. - Т. 330. - № 7. - С. 130-139.

59. Wilson M.J. The origin and formation of clay minerals in soils: past, present and future perspectives // Clay Minerals. - 1999. V. 34. - P. 7-25. DOI: 10.1180/000985599545957.

60. Zaunbrecher L.K., Cygan R.T., Elliott W.C. Molecular simulation of cesium and rubidium adsorption on weathered micaceous minerals // The Journal of Physical Chemistry: A. - 2015. V. 119. - P. 5691-5700. DOI: $10.1021 /$ jp512824k

61. Tritium and radiocarbon in the western North Pacific waters: postFukushima situation / J. Kaizer, M. Aoyama, Yu. Kumamoto, M. Molnar, L. Palcsu, P.P Povinec // Journal of Environmental Radioactivity. - 2018. - V. 184-185. - P. 83-94.

62. Impact of the Fukushima accident on tritium, radiocarbon and radiocesium levels in seawater of the western North Pacific Ocean: a comparison with pre-Fukushima situation / P.P Povinec, L. Liong Wee Kwong, J. Kaizer, M. Molnar, M. Hies, L. Palcsu, L. Papp, M.K. Pham, P. Jean-Baptiste // Journal of Environmental Radioactivity. - 2017. - V. 166. - P. 56-66.

63. Song J.H. An assessment on the environmental contamination caused by the Fukushima accident // Journal of Environmental Management. - 2018. - V. 206. - P. 846-852.

64. Технико-экономические характеристики технологий очистки воды от трития методом химического изотопного обмена в системе вода-водород / А.И. Костылев, И.С. Ледовской, Э.П. Магомедбеков, М.Б. Розенкевич, Ю.А. Сахаровский, И.Л. Селиваненко, А.И. Соболев, С.Н. Флоря // Радиохимия. 2014. - T. 56. - № 5. - С. 450-454.

65. Использование раствора кремниевой кислоты для создания противофильтрационной завесы в песчаном горизонте / Е.П. Каймин, Е.В. Захарова, Л.И. Константинова, А.А. Зубков, В.В. Данилов // Геоэкология, инженерная геология, гидрогеология, геокриология. - 2007. - № 2. - С. 137-142.

Поступила 23.06.2021 2.

\section{Информация об авторах}

Антоненко М.В., кандидат технических наук, заместитель главного инженера, Горно-химический комбинат.

Беспала E.B., кандидат физико-математических наук, начальник отдела научно-исследовательской деятельности и технологического сопровождения вывода из эксплуатации, Горно-химический комбинат.

Мышкин В.Ф., доктор физико-математических наук, профессор отделения ядерного топливного цикла инженерной школы ядерных технологий, Национальный исследовательский Томский политехнический университет.

Павлюк A.O., кандидат физико-математических наук, руководитель группы Научно-исследовательских и опытно-конструкторских работ, АО «Опытно-демонстрационный центр вывода из эксплуатации уранграфитовых ядерных реакторов».

Котляревский С.Г., ведущий инженер группы Научно-исследовательских и опытно-конструкторских работ АО «Опытно-демонстрационный центр вывода из эксплуатации уран-графитовых ядерных реакторов».

Захарова E.B., кандидат химических наук, заведующая лабораторией экологических проблем обращения с радиоактивными и токсичными отходами Института физической химии и электрохимии им. А.Н. Фрумкина Российской академии наук.

Волкова А.Г., кандидат химических наук, научный сотрудник лаборатории экологических проблем обращения с радиоактивными и токсичными отходами Института физической химии и электрохимии им. А.Н. Фрумкина Российской академии наук.

Беспала Ю.P., аспирант отделения ядерного топливного цикла инженерной школы ядерных технологий, Национальный исследовательский Томский политехнический университет; инженер, Горно-химический комбинат. 
UDC 631.438.2; 544.034.24; 532.5-1/-9

\section{POSSIBILITY OF USING CLAY-BASED BARRIER MATERIALS FOR LOCALIZING THE CONSEQUENCES OF RADIATIONS ACCIDENTS (FOR EXAMPLE, THE FUKUSHIMA DAIICHI NPP)}

\author{
Mikhail V. Antonenko1, \\ antonenkomv26@mail.ru
}

Evgeny V. Bespala1, bespala_evgeny@mail.ru

Vyacheslav F. Myshkin², gos100@tpu.ru

\section{Alexander 0. Pavlyuk ${ }^{3}$,} seversknet@rambler.ru

\author{
Sergey G. Kotlyarevskiy ${ }^{3}$, \\ skotkyarevkiy@rambler.ru
}

\section{Elena V. Zakharova ${ }^{4}$,} zevchem@rambler.ru

Anna G. Volkova4, anna.agv@yandex.ru

\section{Yuliya R. Bespala2,1,} yrbespala@gmail.com

${ }^{1}$ Mining and Chemical Combine,

53, Lenin street, Zheleznogorsk, 662972, Russia.

2 National Research Tomsk Polytechnic University, 30, Lenin avenue, Tomsk, 634050, Russia.

3 Pilot and Demonstration Center for Uranium-Graphite Nuclear Reactor Decommissioning, 179a, Avtodoroga 13 street, Seversk, 636000, Russia.

${ }^{4}$ A.N. Frumkin Institute of Physical chemistry and Electrochemistry RAS, 31, Leninskiy avenue, Moscow, 119071, Russia.

The relevance of the research topic is caused by the need to develop new innovative barrier materials with anti-filtration and anti-migratory properties to localize the consequences of the disaster at the Fukushima Daiichi NPP.

The main aim of the study is the review of the possibility of using domestic technologies for localization of radionuclides inside the points of placement of radioactive waste and nuclear materials (corium) to solve the problem of migration of radionuclides at the FukushimaDaiichi NPP.

Methods: mathematical modeling of radionuclides migration from the active zone of the destroyed power units of the Fukushima Daiichi NPP through clay-containing safety barriers.

The results. The paper presents the results of consideration of possibility of using barrier materials for localizing the consequences of radiations accidents. Using the safety clay-based barriers and gelling solutions to prevent the underground migration of radionuclides from destroyed power units to environment was suggested according to positive domestic experience. Accident on nuclear power plant Fukushima-1, occurred on 11 March 2011, was chosen as an example of such a situation. Currently this object is the area for working out the technology and approaches to eliminate the radiation accidents. It was shown that the inflow of radioactive contamination into the ocean is caused by groundwater, rainwater and cooling water, which is daily pumped into the damaged core. Disadvantages of the system used by the safety barrier based on ground frosts were described. On the basis of positive domestic experience, the use of clay-containing safety barriers was proposed to prevent migration of radionuclides from destroyed power units to the ocean. Clay-content materials based on vermiculite, perlite, zeolite, schungite and their sorption characteristics were determined for these purposes. The results of modeling the migration of the most active radionuclides ( $\mathrm{Pu}, \mathrm{Cs}, \mathrm{Sr}, \mathrm{U})$ through the described barrier materials were presented. The possibility of using the safety barrier based on a mixture of clays was shown. The width of such a barrier does not exceed $3,7 \mathrm{~m}$ (determined by the rate of migration of uranium). The total volume of clay-based material barrier required to prevent migration of radionuclides is $\sim 145900 \mathrm{~m}^{3}$.

\section{Key words:}

Fukushima Daiichi NPP, accident, safety barriers, clay, migration, radionuclide.

\section{REFERENCES}

1. Bolshov L.A. Avariya na AES «Fukusima-1»: Opyt reagirovaniya $i$ uroki [Accident at Fukushima-1 NPP: response and lessons learned]. Moscow, Nauka Publ., 2013. 246 p.

2. Aron D.V., Pavlova M.V., Panchenko S.V. Estimates of the scale of the social and economic consequences of the accident at the nuclear power plant in Fukushima Prefecture. Proceedings of the Academy of Sciences. Power engineering, 2013, no. 5, pp. 65-71. In. Rus.

3. Brumfiel G. Fukushima: fallout of fear. Nature, 2013, vol. 493, no. 7432, pp. 290-293.

4. Fujii Y., Satake K., Sakai S., Shinohara M., Kanazawa T. Tsunami source of the 2011 off the Pacific coast of Tohoku Earthquake. Earth, Planets and Space, 2011, vol. 63, no. 7, pp. 815-820.
5. Tong L.L. Hydrogen risk for advanced PWR under typical severe accidents induced by DVI line break. Annals of Nuclear Energy, 2016, vol. 94, pp. 325-331.

6. Wang D., Cao X. Preliminary analysis of hydrogen distribution during severe accident induced by loss of coolant accident. International Conference on Nuclear Engineering, Proceedings, ICONE, 2017, vol. 8. DOI: 10.1115/ICONE25-66497.

7. Tanabe F. Analyses of core melt and re-melt in the Fukushima Daiichi nuclear reactors. Journal of Nuclear Science and Technology, 2012, vol. 49, no. 1, pp. 18-36.

8. Steinhauser G., Brandl A., Johnson T.E. Comparison of the Chernobyl and Fukushima nuclear accidents: a review of the environmental impacts. Science of the Total Environment, 2014, vol. 470-471, pp. 800-817. 
9. Ahlswede J., Hebel S., Ross J.O., Schoetter R., Kalinowki M.B. Update and improvement of the global krypton-85 inventory. Journal of Environmental Radioactivity, 2013, vol. 115, pp. 34-42.

10. Stohl A., Seibert P., Wotawa G. The total release of xenon-133 from the Fukushima Dai-ichi nuclear power plant accident. Journal of Environmental Radioactivity, 2012, vol. 112, pp. 155-159.

11. Ten Hoeve J.E., Jacobson M.Z. Worldwide health effects of the Fukushima Daiichi nuclear accident. Energy and Environmental Science, 2012, no. 5, pp. 8743-8757.

12. Winiarek V., Bocquet M., Saunier O., Mathieu A. Estimation of errors in the inverse modeling of accidental release of atmospheric pollutant: application to the reconstruction of the cesium-137 and iodine-131 source terms from the Fukushima Daiichi power plant. Journal of Geophysical Research: Atmosphere, 2012, vol. 117, pp. 1-16. DOI: 10.1029/2011JD016932.

13. Hamada N., Ogino H. Food safety regulations: what we learned from the Fukushima nuclear accident. Journal of Environmental Radioactivity, 2012, vol. 111, pp. 83-99.

14. Chino M., Nakayama H., Nagai H., Terada H., Katata G., Yamazawa $\mathrm{H}$. Preliminary estimation of release amounts of 131I and 137Cs accidentally discharged from the Fukushima Daiichi nuclear power plant into the atmosphere. Journal of Nuclear Science and Technology, 2011, vol. 48, no. 7, pp. 1129-1134.

15. Stohl A., Seibert P., Wotawa G., Arnold D., Burkhar J.F., Eckhardt S. Xenon-133 and caesium-137 releases into the atmosphere from the Fukushima Dai-ichi nuclear power plant: determination of the source term, atmospheric dispersion, and deposition. Atmos pheric Chemistry and Physics, 2011, vol. 11, pp. 28319-28394.

16. Zheng Jian, Tagami Keiko, Watanabe Yoshito, Uchida Shigeo, Aono Tatsuo, Ishii Nobuyoshi, Yoshida Satoshi, Kubota Yoshihisa, Fuma Shoichi, Ihara Sadao. Isotopic evidence of plutonium release into the environment from the Fukushima DNPP accident. Scientific Reports, 2012, vol. 2. DOI: 10.1038/srep00304.

17. Yoshida N., Takahashi Y. Land-surface contamination by radionuclides from the Fukushima Daiichi nuclear power plant accident. Elements, 2012, vol. 8, pp. 201-206.

18. Lapage H., Evlard O., Onda Y., Lefevre I., Laceby J.P., Avrault S. Depth distribution of cesium-137 in paddy field across the Fukushima pollution plume in 2013. Journal of Environmental Radioactivity, 2015, vol. 147, pp. 157-164

19. Evrard O., Laceby J.P., Lepage H., Onda Y., Gerdan O., Ayrault S Radiocesium transfer from hillslopes to the Pacific Ocean after the Fukushima Nuclear Power Plant accident: a review. Journal of Environmental Radioactivity, 2015, vol. 148, pp. 92-110.

20. Zubekhina B.Y., Burakov B.E. Leaching of actinides and other radionuclides from matrices of Chernobyl "lava" as analogues of vitrified HLW. Journal of Chemical Thermodynamics, 2017, vol. 114 pp. 25-29.

21. Fujiwara H., Kuramochi H., Nomura K., Maeseto T., Osako M. Behavior of radioactive cesium during incineration of radioactively contaminated wastes from decontamination activities in Fukushima. Journal of Environmental Radioactivity, 2015, vol. 178-179, pp. 290-296.

22. Wu J. Impacts of Fukushima Daiichi Nuclear Power Plant accident on the Western North Pacific and the China Seas: evaluation based on field observation of 137Cs. Marine Pollution Bulletin, 2018, vol. 127 , pp. $45-53$.

23. Ramzaev V.P., Ivanov S.A., Goncharova Yu.N., Vishnyakova N.M., Sevastyanov A.V. Investigation of radioactive contamination of marine biota in connection with the accident at the Fukushima-1 NPP. Radiation hygiene, 2012, vol. 4, no. 4, pp. 5-11 In Rus.

24. Interactive world map. Google. Available at: https://www google.ru/maps/search/Fukushima+NPP/@37.421553,141.030436 $6,988 \mathrm{~m} / \mathrm{data}=! 3 \mathrm{~m} 1 ! 1 \mathrm{e} 3$ (accessed 20 December 2020)

25. Current status of Fukushima Daiichi NPS. Efforts for Decommissioning and Contaminated Water Control, 2015. Available at http://www.mofa.go.jp/files/000069784.pdf (accessed 29 November 2019).

26. Butenko A.I. Violation of levels and barriers of deep-level protection at the Fukushima nuclear power plant. Eastern European Journal of Advanced Technology, 2012, vol. 2/8, no. 56, pp. 46-51. In Rus.

27. Pavliuk A.O., Kotlyarevskiy S.G., Bespala E.V., Zakarova E.V., Rodygina N.I., Ermolaev V.M., Proshin I.M., Volkova A.G. Ex- perimental simulation of the radionuclide behaviour in the process of creating additional safety barriers in solid radioactive waste repositories containing irradiated graphite. IOP Conf. Series: Materials Science and Engineering, 2016, no. 142, pp. 1-7.

28. Kondrashova A.A., Andryushchenko N.D., Zakharova E.V., Tyupina E.A. Sorption characteristics of apatite and vermiculite in relation to cesium and strontium radionuclides. Successes in chemistry and chemical technology, 2016, vol. 30, no. 6(175), pp. 56-58. In Rus.

29. Bayulken S., Bascetin E., Guclu K., Apak R. Investigation and modeling of cesium(I) adsorption by Turkish clays: bentonite, zeolite, sepiolite, and kaolinite. Environmental Progress \& Sustainable Energy, 2011, vol. 30, no, 1, pp. 70-80.

30. Yoshikawa E., Komine H., Goto S. Evaluation on hydraulic conductivity of heavy bentonite-based slurry for using on decommissioning of the Fukushima Daiichi Nuclear Power Station. ICEG 2018: Proceedings of the 8th International Congress on Environmental Geotechnics, 2018, vol. 3, pp. 105-112. DOI: 10.1007/978981-13-2227-3 13.

31. Yoshikawa E., Komine H., Goto S., Yoshimura M., Suzuki A., Narushima S., Arai Y., Ukiie S., Sakoda Y., Nagae Y. The quantitative evaluation for radiation shielding capabilities of soil materials. Journal of Japan Society of Civil Engineers, Ser. C (Geosphere Engineering), 2017, vol. 73 (4), pp. 342-354. DOI: 10.2208 /jscejge. 73.342

32. Guggenheim S., Adams J.M., Bain D.C., Bergaya F., Bergaya M.F., Brigatti M., Drits V.A., Formoso M.L.L., Galan E., Kogure T., Stanjek H. Summary of recommendations of Nomenclature Committees relevant to clay mineralogy: report of the Association Internationale Pour L'etude des Argiles (AIPEA) nomenclature committee for 2006. Clays and Clay Minerals, 2006, vol. 54, no. 6 , pp. 761-772. DOI: 10.1180/0009855064140225.

33. Krupskaya V.V., Biryukov D.V., Belousov P.E., Lehov V.A., Romanchuk A.Yu., Kalmykov S.N. Use of Natural Clay Materials to Increase Nuclear and Radiation Safety of Nuclear Legacy Facilities. Radioactive Waste, 2018, no. 2 (3), pp. 30-43. In Rus.

34. Grazulis S., Daskevic A., Merkys A., Chateigner D., Lutterotti L., Quiro's M., Serebryanaya N.R., Moeck P., Downs R.T., Le Bail A. Crystallography open database (COD): an open-access collection of crystal structures and platform for world-wide collaboration. Nucleic Acids Research, 2012, vol. 40, pp. 420-427. DOI: 10.1093/nar/gkr900.

35. Pavliuk A.O., Kotlyarevskiy S.G., Bespala E.V., Zakharova E.V., Ermolaev V.M., Volkova A.G. Experience of on-site disposal of production uranium-graphite nuclear reactor. Journal of Environmental Radioactivity, 2018, vol. 184-185, pp. 22-31.

36. Izmestiev A., Pavliuk A., Kotlyarevsky S. Application of void-free filling technology for additional safety barriers creation during uranium-graphite reactors decommissioning. Advanced Materials Research, 2015, vol. 1084, pp. 613-619.

37. Chubreev D.O., Kuznetsov G.V. Using clay materials for developing safety barrier of decommissioning $\mathrm{AD}$ reactor. Bulletin of the Tomsk Polytechnic University. Geo Assets Engineering, 2016, vol. 327, no. 2, pp. 83-87. In Rus.

38. Antonenko M.V., Chubreev D.O., Kuznetsov G.V. Modeling of radiocarbon diffusion from the active zone of the decommissioned PUGP AD. Atomic Energy, 2015, vol. 118, pp. 63-68. In Rus.

39. Mokrov Yu.G., Mokrov K.Yu. Modeling of atmospheric transfer of radionuclides in the form of water aerosols from the surface area of water bodies using the example of Lake Karachay, Russia. Radiation and Environmental Biophysics, 2019, vol. 58, pp. 393-405. DOI: 10.1007/s00411-019-00799-w.

40. Mokrov Yu.G., Aleksahin A.I. Monitoring is safety basis for the conservation of the Karachay reservoir. Radioactive waste, 2018, no. 3 (4), pp. 60-68. In Rus.

41. Batuk D.N., Shiryav A.A., Kalmykov S.N., Zaharova E.V., Teterin Yu.A., Batuk O.N. Interaction $\mathrm{U}, \mathrm{Np}$ and $\mathrm{Pu}$ with colloidal particles $\mathrm{SiO}_{2}$. Radiochemistry, 2012, vol. 54, no. 6, pp. 522-526.

42. Maekawa A., Momoshima N., Sugihara S., Ohzawa R., Nakama A. Analysis of ${ }^{134} \mathrm{Cs}$ and ${ }^{137} \mathrm{Cs}$ distribution in soil of Fukushima prefecture and their specific adsorption on clay minerals. Journal of Radioanalytical and Nuclear Chemistry, 2015, vol. 303, pp. 1485-1489.

43. Andryushchenko N.D., Safonov A.V., Babich T.L., Ivanov P.V., Konevnik Yu.V., Kondrashova A.A., Proshin I.M., Zakharova E.V. Sorption characteristics of the materials of the filtration barrier in 
the upper aquifers contaminated with radionuclides. Radiochemistry, 2017, vol. 59, no. 4, pp. 361-370. In Rus.

44. Sabodina M.N., Kalmykov S.N., Artem'eva K.A., Zakharova E.V., Sapozhnikov Yu.A. Behavior of $\mathrm{Cs}, \mathrm{Np}(\mathrm{V}), \mathrm{Pu}(\mathrm{IV})$, and $\mathrm{U}(\mathrm{VI})$ in pore water of Bentonite. Radiochemistry, 2006, vol. 48, no. 5, pp. 488-492.

45. Leng Ya., Henderson M.J., Courtois J., Li H., Xiong K., Tuo X., Yan M. Sorption of plutonium on geological materials associated with a Chinese radioactive waste repository: influence of $\mathrm{pH}$. Journal of Radioanalytical and Nuclear Chemistry, 2016, vol. 308 , pp. 895-903.

46. Konoplev A., Golosov V., Wakiyama Y., Takase T., Yoschenko V., Yoshihara T., Parenyuk O., Cresswell A., Ivanov M., Carradine M., Nanba K., Onda Y. Natural attenuation of Fukushima-derived radiocesium in soils due to its vertical and lateral migration. Journal of Environmental Radioactivity, 2018, vol. 186, pp. 23-33.

47. Houn S., Hayashi S., Laceby J.P., Tsuji H., Onda Y., Evrard O. Source dynamics of radiocesium-contaminated particulate matter deposited in an agricultural water reservoir after the Fukushima nuclear accident. Science of the Total Environment, 2018, vol. 612, pp. $1079-1090$

48. Mironenko V.A., Rumynin V.G. Problemy gidrogeoekologii. Monografiya v 3-kh tomakh. T. 1. Teoreticheskoe izuchenie i modelirovanie geomigratsionnykh protsessov [Problems of hydrogeoecology. Monograph in 3 vol. Vol. 1. Theoretical study and modeling of geomigration processes]. Moscow, Moscow State Mining University Publ., 1998. 611 p.

49. Shackelford C.D., Moore S.M. Fickian diffusion of radionuclides for engineered containment barriers: Diffusion coefficients, porosities, and complicating issues. Engineering Geology, 2013, vol. 152 , pp. 133-147.

50. Kirishima A., Hirano M., Akiyama D., Sasaki T., Sato N. Study on the leaching behavior of actinides from nuclear fuel debris. Journal of Nuclear Materials, 2018, vol. 502, pp. 169-176.

51. Steinhauser G., Merz S., Hainz D., Sterba J.H. Artificial radioactivity in environmental media (air, rainwater, soil, vegetation) in Austria after the Fukushima nuclear accident. Environmental Science and Pollution Research, 2013, vol. 20, no. 4, pp. 2527-2537.

52. Van Loon L.R., Mibus J. A modified version of Archie's law to estimate effective diffusion coefficients of radionuclides in argillaceous rocks and its application in safety analysis studies. Applied Geochemistry, 2015, vol. 59, pp. 85-94.

53. Kudryashov N.A., Serebryakova I.E. Mathematical modeling of migration of long-lived radionuclides in soil as a result of radioactive fallout. Atomic Energy, 1993, vol. 74, pp. 243-247. In Rus.

54. Pavlyuk A.O., Kotlyarevskiy S.G., Bespala E.V., Volkova A.G., Zakharova E.V., Andryushchenko N.D. Modelling migration process of long-lived radionuclides from graphite radioactive waste Bulletin of the Tomsk Polytechnic University, Geo Assets Engineering, 2017, vol. 328, no 4, pp. 75-84. In Rus.
55. Choy K.K.H., Ko D.C.K., Cheung C.W., Porter J.F., McKay G. Film and intraparticle mass transfer during the adsorption of metal ions onto bone char. Journal of Colloid and Interface Science, 2004, vol. 271, pp. 284-295. DOI: 10.1016/j.jcis.2003.12.015.

56. Zuo R., Teng Ya., Wang J., Hu Q., Guo M. Experimental validation of retardation of tritium migration in the Chinese Loess Media. Water Air and Soil Pollution, 2011, vol. 215, pp. 497-506. DOI: 10.1007/s11270-010-0494-x.

57. Dmitriyeva E.D., Goryacheva A.A., Syundyukova K.V., Muzafarov E.N. Sorption capacity of natural and modified montmorillonite with respect to copper ions in the presence of organic acids]. Sorbtsionnye i khromatograficheskie protsessy, 2016, vol. 6, no. 6, pp. 813-820. In Rus.

58. Antonenko M.V., Leonov A.V., Bespala E.V., Chubreev D.O., Bespala Yu.R. Application of electroosmotic effect for unwatering barriers during decommissioning nuclear legacy. Bulletin of the Tomsk Polytechnic University. Geo Assets Engineering, 2019, vol. 330, no. 7, pp. 130-139. In Rus.

59. Kaizer J., Aoyama M., Kumamoto Yu., Molnar M., Palcsu L., Povinec P.P. Tritium and radiocarbon in the western North Pacific waters: post-Fukushima situation. Journal of Environmental Radioactivity, 2018, vol. 184-185, pp. 83-94.

60. Wilson M.J. The origin and formation of clay minerals in soils: past, present and future perspectives. Clay Minerals, 1999, vol. 34, pp. 7-25. DOI: 10.1180/000985599545957.

61. Zaunbrecher L.K., Cygan R.T., Elliott W.C. Molecular Simulation of Cesium and Rubidium Adsorption on Weathered Micaceous Minerals. The Journal of Physical Chemistry: A, 2015, vol. 119, pp. 5691-5700. DOI: 10.1021/jp512824k.

62. Povinec P.P., Liong Wee Kwong L., Kaizer J., Molnar M., Hies M., Palcsu L., Papp L., Pham M.K., Jean-Baptiste P. Impact of the Fukushima accident on tritium, radiocarbon and radiocesium levels in seawater of the western North Pacific Ocean: a comparison with pre-Fukushima situation. Journal of Environmental Radioactivity, 2017, vol. 166, pp. 56-66.

63. Song J.H. An assessment on the environmental contamination caused by the Fukushima accident. Journal of Environmental Management, 2018, vol. 206, pp. 846-852.

64. Kostylev A.I., Ledovskoy I.S., Magomedbekov E.P., Rozenkevich M.B., Saharovskiy Yu.A., Selivanenko I.L., Sobolev A.I., Florya S.N. Technical and economic characteristic of the technology of water purification from tritium by chemical isotope exchange in a watersolution system. Radiochemistry, 2014, vol. 56, no. 5, pp. 450-454.

65. Kaimin E.P., Zakharova E.V., Konstantinova L.I., Zubkov A.A., Danilov V.V. Ispolzovanie rastvora kremnevoy kisloty dlya sozdaniya protivofiltratsionnoy zavesy $\mathrm{v}$ peschanom gorizonte [Use of a solution of silicic acid to create an anti-filtration curtain in the sand horizon]. Geoecology, engineering geology, hydrogeology, geocryology, 2007, no. 2, pp. 137-142.

Received: 23 June 2021.

\section{Information about the authors}

Mikhail V. Antonenko, Cand. Sc., deputy chief engineer, Mining and Chemical Combine.

Evgeny V. Bespala, Cand. Sc., head of department, Mining and Chemical Combine.

Vyacheslav F. Myshkin, Dr. Sc., professor, National Research Tomsk Polytechnic University.

Alexander O. Pavlyuk, Cand. Sc., head of the group, Pilot and Demonstration Center for Uranium-Graphite Nuclear Reactor Decommissioning.

Sergey G. Kotlyarevskiy, leading engineer, Pilot and Demonstration Center for Uranium-Graphite Nuclear Reactor Decommissioning.

Elena V. Zakharova, Cand. Sc., head of the laboratory, Russian academy of sciences A.N. Frumkin Institute of Physical chemistry and Electrochemistry RAS.

Anna G. Volkova, Cand. Sc., researcher, Russian academy of sciences A.N. Frumkin Institute of Physical chemistry and Electrochemistry RAS.

Yuliya R. Bespala, postgraduate student, National Research Tomsk Polytechnic University; engineer, Mining and Chemical Combine. 